\title{
DEVELOPING A FRAMEWORK FOR SYSTEMIC TRANSFORMATION OF THE CONSTRUCTION INDUSTRY
}

\author{
Antti Peltokorpi ${ }^{1}$, Olli Seppänen ${ }^{2}$, Joonas Lehtovaara ${ }^{3}$, Ergo Pikas ${ }^{4}$, and Otto \\ Alhava $^{5}$
}

\begin{abstract}
In the era of customer-driven and digitalized businesses, the construction industry has still demonstrated inadequate performance development. This research aims to disentangle the industry's current problems and present justified paths toward sustainable improvement. Following the design science research approach, the paper develops a conceptual framework about the path toward the systemic transformation of the construction industry. We first argue how current efforts to improve construction system are often limited to changes in sub-systems, namely in a) products, b) processes, c) organizing and people, d) information systems, or e) value creation models, therefore lacking a systemic approach needed for significant and sustainable improvements. We then propose a framework that underlines the need to simultaneously develop all the identified five sub-systems to achieve successful transformation. Three cases are presented as partial solutions to such systemic innovations. The paper provides new insights into how a systemic approach could be utilized when transforming the construction industry. More specifically, takt production is identified as one key driver for systemic change. The theoretical contribution lies in the identified five sub-systems and their parallel development as a source for sustainable transformation. However, the paper is conceptual and limited to three partial cases. More empirical research is needed to validate the framework and to specify the most effective transformation paths.
\end{abstract}

\section{KEYWORDS}

Systemic innovation, transformation, construction industry, design science approach.

\section{INTRODUCTION}

The construction industry has been criticized for its lack of innovation and future-oriented investments. This has led to slow development of the whole sector and lagging behind other industries, for example, in terms of productivity (e.g., Barbosa et al. 2017). Many

\footnotetext{
1 Assistant Professor, Department of Civil Engineering, Aalto University, Finland, antti.peltokorpi@aalto.fi, orcid.org/0000-0002-7939-6612

2 Associate Professor, Department of Civil Engineering, Aalto University, Finland, olli.seppanen@aalto.fi, orcid.org/0000-0002-2008-5924

3 Doctoral Candidate, Department of Civil Engineering, Aalto University, Finland, joonas.lehtovaara@ aalto.fi, orcid.org/0000-0002-4761-3811

4 Assistant Professor, Department of Civil Engineering and Architecture, Tallinn University of Technology, Estonia, ergo.pikas@ taltech.ee, orcid.org/0000-0001-5691-685X

5 CTO, Fira Group Oy, Vantaa, Finland, otto.alhava@ fira.fi, orcid.org/0000-0001-5691-685X
} 
contractors have had enormous project management problems in recent years, which has traditionally been the general contractors' capability. Together with quality issues, these problems raise the question about the sector's systemic challenges: are there some fundamental reasons why in the era of customer-driven and disruptive digitalized businesses, the construction industry has demonstrated an inadequate and unsatisfactory development?

Systemic innovations form a way of overcoming these persistent challenges. Systemic innovations are industry-defining, mold-breaking changes that diffuse across companies and specialties, often resulting in fundamental changes in how companies operate within the industry (Taylor and Levitt 2004). Systemic innovations often call for an extended, collaboratively coordinated cross-company effort that requires commitment from several actors in the supply network (Lavikka et al. 2020), making the implementation burdensome and less likely to succeed than incremental innovations that fit within the predefined boundaries of the industry. Within construction, the industry's fragmented and risk-averse nature sets barriers for employing systemic innovations (Sheffer 2011): fragmentation hinders long-lasting collaboration in innovation activities, and risk aversion leads to low R\&D investments in general. However, when successful, systemic innovations often offer superior and long-lasting performance benefits compared to incremental innovations (Hall and Lehtinen 2015).

This paper aims to disentangle the construction sector's current problems and then present justified paths toward systemic improvement. The contribution to knowledge is not in addressing individual issues or solutions but in emphasizing systemic and integrated solutions to the known challenges. In practice, this means that multiple subsystems should be simultaneously developed to radically and sustainably improve the sector's performance.

Regarding the sub-systems, we would not refer directly to different roles or professionals in the construction ecosystem as they often mirror the ongoing practices. Instead, we follow the logic of Nightingale (2000) about the product-processorganization relationships in complex development projects and argue that innovation in construction is most likely successful when these different focuses of development, such as products and processes, are developed simultaneously in an integrated manner. These sub-systems have traditionally been managed by different actors, such as clients, designers, contractors, and product suppliers, client or general contractor often acting as a system integrator. Consequently, a systemic transformation likely requires changes in the actors' roles and responsibilities and increased collaboration between stakeholders.

In practice, this paper develops a conceptual framework about the path toward systemic innovations in the construction sector. We utilize the design science approach (e.g., Ravitch and Riggan 2012; Torraco 2016) first to describe the status of the construction system and then to progress on developing a solution framework that is informed by systemic innovation thinking. In each phase, when identifying the most relevant sub-systems, when describing the status of the system, and when developing a framework as a consequence of the status and the systemic thinking, the authors' insights are discussed and validated in a group of 20 CEOs representing various AEC companies of the Finnish construction ecosystem. In the end, we present three existing partial solutions in which the logic of systemic innovation and transformation is implemented in practice.

This paper is organized as follows: We first present a current construction practice diagnosis, highlighting five broken sub-systems. Next, we provide principles to help 
understand the root causes for the breakage of these sub-systems. We then conceive a solution framework that emphasizes appropriate combinations of sub-system improvements. Next, we present partial solutions using examples from actual cases to help pave the sector's progress toward systemic transformation. Finally, we conclude by discussing on implications of findings on research and practice.

\section{DIAGNOSIS: FIVE BROKEN SUB-SYSTEMS}

We argue that solving issues and symptoms one-by-one is not sufficient for the construction sector's sustainable development. Following Bertelsen's (2003) research, the view of complex adaptive systems (CAS) should be in focus when discussing new management paradigms in construction. In other words, to manage the inherent complexity of construction, a holistic understanding of multiple sub-systems and their interconnected problems is needed.

In this paper, we focus on the five broken sub-systems: 1) product, 2) process, 3) people and organizing, 4) information, and 5) value creation. The first three sub-systems, product, process and organizing, originate from the key elements of the complex development projects (Nightingale 2000) and the three types of innovation (Boer and During 2001). The CEO group suggested to add the people aspect in organizing to emphasize the role of individuals and professional groups in innovating and disseminating innovations. Then, information systems were separated from other processes, as they are more suitable for technological developments and benefit from field-specific standards. Finally, value creation aspect was added to underline customer value as a fundamental objective of any lean system.

\section{Broken Product}

Buildings are complex products with a large variety of incompatible sub-products and materials. Parts must fit geometrically and support the system's function as a whole. Unfortunately, the lack of systematic study and evaluation of design alternatives leads to incompatibility issues. The sub-products have complex interfaces, and there are often coordination issues between the sub-products. There are large and unaligned engineering tolerances in building structures and products. This all means, that product development, such as innovating pre-fabrication solutions, is often hindered by existing project processes, fixed roles of professionals, and disruptions of innovations to some actors' existing business models (e.g., Lavikka et al. 2021).

\section{BROKEN PROCESS}

Although lean construction aims to improve the process, most projects are built based on ad hoc processes and practices. There is a lack of integration of value chains and limited engagement and integration of stakeholders. Limited communication and collaboration lead to a lack of flow in design and production processes. Decision-making is often not systematic, and typically continuous learning from project to project is limited. Recent advancements, e.g., in adopting takt production, have improved the processes (Lehtovaara et al. 2021). However, successful takt production implementation on-site often requires simultaneous product development (Chauhan et al. 2018), new organization and collaboration methods (Kujansuu et al. 2019), and management of logistic processes (Tetik et al. 2019a). 


\section{Broken Organizations and Management of People}

In most projects, clients still prefer traditional procurement and contracting models, such as Design-Bid-Build, which have led to underdeveloped relationships and distrust. Organizations tend to work in silos in both design and construction. These silos originate from the systems and cultures in which construction managers and design disciplines are educated. Other stakeholders, for example, users and material suppliers, are not integrated into the process. Having multiple different professionals and actors in the joint innovation effort has promised to result in remarkable transformations (Lavikka et al. 2020).

\section{BROKEN INFORMATION SYSTEMS}

In construction projects, information is located and distributed in different and incompatible information systems. There is no adequate information management standard that could formalize the information from the construction process. A gap exists for linking the on-site construction operation information with the supporting processes (Zheng et al. 2020). The lack of interoperable systems hinders the development of a realtime understanding of the current state. Furthermore, most of these systems rely on manual data entry and updating. There are technical, organizational, and cultural barriers to sharing data and information between actors and processes in the projects.

\section{Broken Value Creation}

Contractors and designers lack customer-driven business models and services. Most of the actors use precisely the same business model to win new business and complete projects profitably (Pekuri et al. 2015). The business models are based on outdated financing instruments and asset-dependence, especially among developers. There is no real business connection between the project delivery and building operation phases. Project actors tend not to have a holistic — but rather a piecemeal—understanding of the customer's requirements and targets.

The consequences of the current practices are that actors have a single-project mindset leading to a lack of scalability in products and production and a lack of learning and continuous improvement. With the current mindset and roles, lifecycle investments are not seen profitable. Contractors' business models are vulnerable and asset-based, in which surprises destroy value. Down-side risks are higher than upside opportunities. In summary, there is no systemic sector-wide development and scalable businesses.

\section{PRINCIPLES FOR SOLUTION}

After diagnosing the construction industry's status, we next present principles in finding solutions for existing challenges. Following the generic lean principles (Liker 2004), the first principle is not only fixing visible and obvious problems but identifying root causes for symptoms and acting on them. This requires asking multiple times "why" to question the existing conventions and practices. Although existing practices may not be completely ineffective, their historical origins mean they may no longer be relevant when applied to current circumstances. The following are examples of such questioning:

- Instead of controlling production on-site, we should ask why these activities are done on-site.

- Instead of solving quality issues on site, we should ask why the issue emerged and was not detected in earlier stages. 
- Instead of managing multi-specialty teams, we should ask why we have so many professions with siloed cultures and languages.

In addition to those questions about the "big picture" of construction practices, more specific problems and their origins should be continuously challenged. For example, regarding the products:

- Instead of solving tolerance problems, we should ask why product tolerance requirements are that loose in construction.

- Instead of solving problems with the drying of products on site, we should ask why we have wet products.

The second principle is to look for solutions that exist at the boundaries of the sub-systems. For example, suppose we would like to improve the product. In that case, we should think about what kind of new organizing modes, such as industry actors' roles and contracts, and processes are needed to support the transformation. Similarly, sharing real-time information between the actors within and between projects might be a crucial trigger for a holistic understanding of the projects, and simultaneously, the path to a common language and culture.

\section{FRAMEWORK FOR SYSTEMIC TRANSFORMATION AS A SOLUTION}

Based on the principles mentioned above, we present a framework about the solutions at the sub-system level and systemic and synergistic solutions that integrate simultaneous developments in multiple sub-systems. Figure 1 presents our conceptual framework. Many of these solutions have already been suggested in previous research; however, they are mostly isolated from each other and focused on individual existing problems. Focusing only on a specific sub-system, such as product, process, or information, leads to compromises, poor implementation, and partial solutions.

The most remarkable innovations are systemic, in which multiple challenges are solved simultaneously. For example, integrated design, product, process, and use data (information system), together with modular product architecture (product system) would enable developing integrated or even cyber-physical design and construction capabilities that utilize parametric and algorithmic design and engineering (e.g., Tetik et al. 2019b). These systems' development requires that multiple existing professionals, including architects, engineers, production specialists, and owners, work together for an extended period. By systematically collecting data from the use phase, these solutions can be further developed for new customers. Additional value-adding services and products can be provided during the building's lifecycle. 


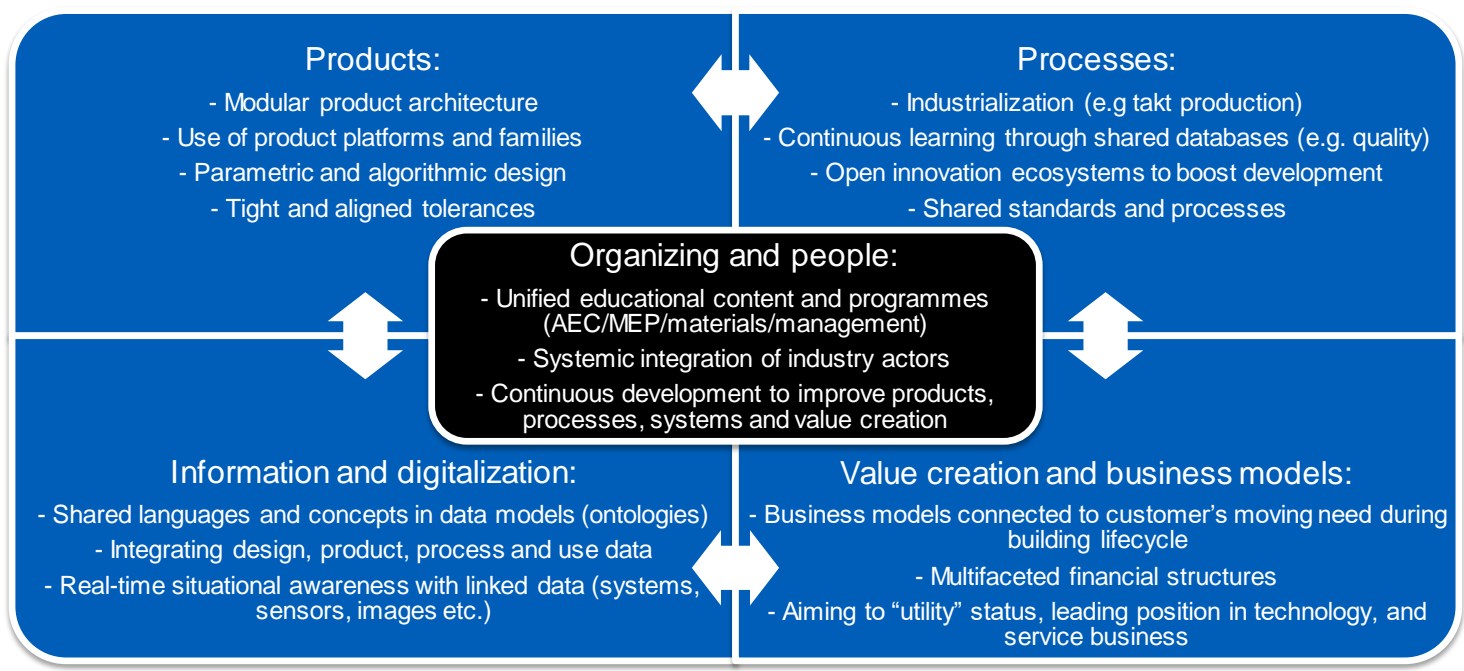

Figure 1: Conceptual framework of integrating sub-system solutions for construction industry transformation.

\section{INTEGRATED PARTIAL SOLUTIONS: CASE EXAMPLES}

We next present three existing solutions which fully or partially follow the logic of systemic innovation and integration of the sub-system solutions.

\section{Project Frog: Ecosystem Around Digital Design Configurator}

Project Frog is located in California, USA; the company has developed a construction ecosystem that integrates product platforms, mass customization, offsite fabrication, systematic processes, and digital technologies to manufacture building components in a controlled environment, transport them to their final location, and assemble them on site. The value proposition to their clients is the speed and scalability from design through manufacturing and construction. Benefits include lead time reduction from project inception to handover, automation of processes, and improved schedule, cost, and quality planning and control.

The critical part of their solution is a building configurator known as a Kit-of-Parts platform. The main idea is that buildings are treated as product platforms, wherein building components are developed, iterated, and reused in the design process to enable a wide variety of buildings. Criteria in designing and developing these components are manufacturability and ease of assembly. This is otherwise known as Design for Manufacturing and Assembly (DfMA). Other criteria include flexibility, automation, and reusability.

This approach relies on interconnected data-centric cloud technology to enable data management at scale. The technology supports the design and engineering with real-time feedback on cost and schedule and enables data flow management from planning and design through manufacturing and construction. This has been achieved by developing interoperable digital systems related to products and processes.

Using Kit-of-Parts and data-centric approaches have enabled the company to automate manufacturing processes. For example, the flow of design information to manufacturing equipment, also known as BIM (building information model) to CAM (computer-aided manufacturing), reduces manual work to process the product and manufacturing information. In addition to automating manufacturing processes, greater automation in the design phase can be achieved. With proper templates, product catalogs, 
property sets, and knowledge catalogs, the development of intermediate information products, including, for example, drawings, specifications, engineering calculations, and detailing, can be automated extensively. Currently, these activities consume a lot of skilled labor hours.

In summary, using a system architecting and building strategy, the company has developed an ecosystem where different sub-systems work together. This has allowed them to develop a new business model with high-quality services to clients and end-users. Over time, more such examples will likely emerge, such as Katerra, which is also located in California.

\section{Bryden Wood: Platform Approach to Construction}

Bryden Wood is a technology-led design company in the UK, bringing together a broad range of specialists from various industries with a vision to deliver high quality sustainable architecture. They aim to close the gap between construction and manufacturing. Today they are considered the UK leader in offsite and advanced construction techniques. At the heart of Bryden Wood's business models is their platform-based approach to construction. Without compromising aesthetic integrity, Bryden Wood seeks to build more quickly, more economically, and with a greater whole life value.

They have used the analogy of platforms from the software and manufacturing companies and adapted it to the context of the built environment. For Bryden Wood, the platform represents a design system, turned into a construction system in factory conditions through standardized routines. The platform comprises a set of standardized components with well-defined interfaces (kits of parts). Yet, components and interfaces are flexible to design, produce, and assemble a great variety of buildings.

This is achieved by breaking down buildings into spaces to identify commonalities across building sectors. For example, based on their analysis, schools, apartments, and healthcare facilities have similar structural spans and ceiling heights. At Bryden Wood, they have defined two common platforms, including small-scale residential and largescale buildings.

The critical part of their business model is software development of building and product configurators used by clients and the general public. The objective is to give users access to configure buildings in hours rather than in weeks using their platform and kits of parts. But the digitalization does not end with the configurator apps. Detailed models can be generated from the configurator apps and taken as input to design, manufacture, and assembly processes. That is, models can be imported to BIM applications to develop designs further. Then information for computer-aided manufacturing can be extracted and fed into manufacturing equipment. The gap between the construction and manufacturing is reduced because of standardized processes and common data platforms.

\section{Digital Takt Production}

Despite primarily serving as a process-based innovation, takt production can be viewed as one key driver for systemic change; with increased maturity, takt planning and control touches almost all aspects of a project system (Lehtovaara et al. 2020). It can be argued that when reaching the highest maturity levels, effective takt production process development is linked to product development (pull-based design management, constructability of designs), value creation (production pacing is matched with client's needs), information flow and digitalization (real-time situational awareness aided with 
digital tools) and learning of organizations and people (a collaboration between actors, continuous improvement, and holistic understanding on how effective project systems operate). Social aspects of location-based systems, such as takt production, can be further enhanced by integrating the Last Planner System $(\odot$ to improve the utilization of tacit knowledge of stakeholders and to provide structure to continuous improvement (Frandson et al. 2014).

Even though takt production can be successfully implemented without digitalization, recent studies (e.g., Alhava et al. 2019) suggest that digital tools can greatly enhance realtime situational awareness, which is necessary to excel with fast-paced takt production control (Lehtovaara et al. 2021). Transparent and up-to-date progress information helps production stakeholders plan and control their actions proactively and collaboratively, enabling efficient flow of processes and operations and effective flow of information (Uusitalo et al. 2019) and material (Tetik et al. 2019a) flows.

In addition to offering the potential for more efficient takt production control and short-term improvement, digitalization can also help to improve long-term learning. As takt production increases in maturity, effective learning from project to projectincluding the process steps from upstream design to downstream use phase - is needed to reach full potential of takt production while driving for systemic transformation. The concept of digital twin construction (DTC; Sacks et al. 2020) has recently captured broad interest, being a potential contributor in forming a comprehensive model for construction management and enabling data-driven management and learning through iterative control loops. In addition to achieving efficient information flow within a single production system, vertical and horizontal utilization of DTC would also greatly enhance information flow through projects and organizations.

\section{CONCLUSIONS}

This paper presents a conceptual framework of integrating sub-system solutions for sustainable construction industry transformation. The proposed framework can be utilized both among researchers and practitioners when developing and implementing new practices in the construction industry. The presented examples suggest that innovation may originate in a specific sub-system, such as in processes (takt production), digital information systems (Project Frog), or products (Bryden Wood). Still, to achieve a genuinely sustainable transformation, modifications are also needed in other sub-systems. Simultaneous improvements in multiple sub-systems require additional investments and resources. However, they may lead to more disruptive innovations and create a competitive advantage that other firms and networks cannot easily imitate.

From a process point of view, one remarkable finding is that takt production could work as a key driver for many systemic changes in the construction ecosystem. Successful implementation of takt production requires that product design, individuals' capabilities, information flow, and value creation among the project actors are aligned. On the other hand, takt production can also be used as a catalyst for innovations in other sub-systems. Collaborative contracts, such as Alliance and Integrated Project Delivery (IPD), have had a similar role in enabling innovations. However, contracts are often project-specific, and therefore their innovation potential for the whole industry is limited. Takt production as a strategic choice of a general contractor could better lead to project-to-project improvements and finally to sustainable transformation.

This research contributes to existing knowledge about systemic innovations in construction, underlining the need for a holistic approach and integration of sub-systems' 
development when transforming the industry. The theoretical contribution lies in the identified five sub-systems and their parallel development as a source for sustainable transformation.

This research is conceptual and limited to three partial cases. Three cases were investigated that are mostly designer-contractor-supplier led, and customer organizations had only a minor role in the innovation teams. It could be argued that customer has a major role in enabling industry transformation, e.g., through collaborative models or by setting new requirements for projects and products. However, more research is needed on customer's possible role in owning the innovation and being responsible for its continuous development. Further conceptual and empirical research is needed about reallife innovation efforts and nuanced mechanisms behind successful transformations and innovations. Comparative studies on successful and failed innovation efforts could also reveal additional insights on the transformations and their implementation.

\section{ACKNOWLEDGEMENTS}

This research was financially and technically supported by the companies of the Aalto University's Building 2030 consortium. The support of those 20 Finnish AEC companies is greatly appreciated. The authors would like to thank the people participating in the workshops for the time invested and knowledge shared.

\section{REFERENCES}

Alhava, O., Rinne, V., Laine, E. \& Koskela, L. (2019). "Can a Takt Plan Ever Survive Beyond the First Contact With the Trades On-Site?” In: Proc. 27th Annual Conference of the International Group for Lean Construction (IGLC). Dublin, Ireland, 3-5 Jul 2019. pp 453-464.

Barbosa, F., Woetzel, J., Mischke, J., Ribeirinho, M. J., Sridhar, M., Parsons, M., Bertram, N. \& Brown, S. (2017). Reinventing construction through a productivity revolution. McKinsey Global Institute.

Bertelsen, S. (2003) "Construction as a Complex System” In: 11th Annual Conference of the International Group for Lean Construction. Virginia, USA, 1-.

Chauhan, K., Peltokorpi, A., Seppänen, O. \& Berghede, K. (2018) "Combining Takt Planning With Prefabrication for Industrialized Construction". In: 26th Annual Conference of the International Group for Lean Construction. Chennai, India, 18-20 Jul 2018. pp 848-857.

Hall, D. M., and T. Lehtinen. (2015). "Agile cost shifting as a mechanism forsystemic innovations". InProc., Engineering Project Organization Conference, 1-15. Edinburgh, Scotland: The Univ. of Edinburgh.

Kujansuu, P; Lehtovaara, J; Grönvall, M; Seppänen, O; Peltokorpi, A. (2019) "Comparison of Collaboration and Trade Partner Commitment in Takt Implementation Cases", 27th Annual Conference of the International Group for Lean Construction, Dublin Ireland.

Lavikka, R., Seppänen, O., Peltokorpi, A., \& Lehtovaara, J. (2020) "Fostering process innovations in construction through industry-university consortium". Construction Innovation, Vol. 20 No. 4, pp. 569-586.

Lavikka, R., Chauhan, K., Peltokorpi, A. and Seppänen, O. (2021) "Value creation and capture in systemic innovation implementation: case of mechanical, electrical and plumbing prefabrication in the Finnish construction sector", Construction Innovation, ahead-of-print. doi.org/10.1108/CI-05-2020-0070. 
Lehtovaara, J., Heinonen, A., Lavikka, R., Ronkainen, M., Kujansuu, P., Ruohomäki, A., Örmä, M., Seppänen, O. \& Peltokorpi, A. (2020) "Takt Maturity Model: From Individual Successes Towards Systemic Change in Finland" In: Proc. 28th Annual Conference of the International Group for Lean Construction (IGLC). Berkeley, California, USA, 6-10 Jul 2020. pp 433-444.

Lehtovaara, J.; Seppänen, O.; Peltokorpi, A.; Kujansuu, P.; Grönvall, M. (2021). "How takt production contributes to construction production flow: A theoretical model." Constr. Manag. Econ., 39, 73-95.

Liker, J. K. (2004) The Toyota Way: 14 Management Principles from the World's Greatest Manufacturer. McGraw-Hill.

Nightingale, P. (2000) "The product-process-organisation relationship in complex development projects". Research Policy, Vol 29, Iss 7-8, pp. 913-930.

Pekuri A, Pekuri L \& Haapasalo H (2015) Business models and project selection in construction companies. Construction Innovation: Information, Process, Management 15(2): 180-197.

Ravitch, S.M., Riggan, M. (2012) Reason \& Rigor: How Conceptual Frameworks Guide Research. SAGE Publications.

Sheffer, D. A. (2011). Innovation in modular industries: Implementing energy-efficient innovations in US buildings. Ph.D. thesis, Dept. of Civil and Environmental Engineering, Stanford University.

Taylor, J. E., and R. E. Levitt. (2004). "A new model for systemic innovationdiffusion in project-based industries". InProc., PMI Research Conf:: Innovations. Newtown Square, PA: Project Management Institute.

Tetik, M. Peltokorpi, A; Seppänen, O; Viitanen, A; Lehtovaara, J. (2019a) "Combining Takt Production With Industrialized Logistics in Construction", 27th Annual Conference of the International Group for Lean Construction, Dublin Ireland.

Tetik, M., Peltokorpi, A., Seppänen, O., Holmström, J. (2019b) "Direct digital construction: Technology-based operations management practice for continuous improvement of construction industry performance". Automation in Construction, Vol. 107, November 2019.

Torraco, R.J., 2016. Writing integrative literature reviews: Using the past and present to explore the future. Human resource development review 15, 404-428.

Uusitalo, P., Seppänen, O., Lappalainen, E., Peltokorpi, A., Olivieri, H. (2019). "Applying Level of Detail in a BIM-Based Project: An Overall Process for Lean Design Management". Buildings, Vol. 9, Issue 5, p. 109-121.

Zheng, Y., Tetik, M., Törmä, S., Peltokorpi, A., Seppänen, O. (2020) A Shared Ontology for Logistics Information Management in the Construction Industry. 37th International Symposium on Automation and Robotics in Construction (ISARC 2020). 